\title{
Synthesis and Biological Activity of 12-Aza-Epothilones (Azathilones) - Non-Natural Natural Products with Potent Antiproliferative Activity
}

\author{
Fabian Feyen $\$$, Jürg Gertscha ${ }^{a}$, Markus Wartmann ${ }^{c}$, and Karl-Heinz Altmann ${ }^{\star a}$ \\ §METTLER TOLEDO Awards 2006 (Oral Presentation)
}

\begin{abstract}
Aza-epothilones ('Azathilones') 1 and $\mathbf{2}$ have been prepared through ring-closing olefin metathesis or macrolactonization-based cyclization reactions. While RCM of the respective dienes $\mathbf{9}$ and $\mathbf{1 2}$ was found to be very effective and produced macrocyclic olefins with high $E$ selectivity, the subsequent reduction of the 9,10-double bond proved to be unexpectedly difficult and low-yielding. Preparation of azathilone 2 was also accomplished via macrolactonization and this approach was found to be more effective. Compound 2 is a highly potent inhibitor of human cancer cell growth in vitro. The activity of this analog is comparable with that of Epo A, both in terms of cytotoxicity against drug-sensitive human cancer cells as well as its tubulin-polymerizing activity. However, in contrast to Epo A, $\mathbf{2}$ is considerably less potent against multidrug-resistant cancer cells.
\end{abstract}

Keywords: 12-Aza-epothilones

\section{Introduction}

Natural products are a unique and highly productive source of lead structures for drug discovery and development, with approximately $50 \%$ of currently marketed drug molecules being derived, either directly or indirectly, from naturally occurring substances. ${ }^{[1]}$ Traditionally, natural products-based drug development has principally relied on the immediate exploitation of compounds obtained directly from natural sources (bacteria, fungi, plants) or structurally related semi-synthetic derivatives thereof. More recently, these approaches have been complemented by novel chemistry-based concepts which aim at expanding the structural scope of natural prod- ucts-based drug discovery. Examples are the de novo construction of libraries of naturalproducts-like compounds through diversityoriented-synthesis (DOS), ${ }^{[2,3]}$ as pioneered by Schreiber, or the design of natural-products-based libraries, a concept introduced by Waldmann in 2002. [4,5] Our own research in the area of natural-products-based lead generation has focused on the development of new biologically active scaffolds through the extensive structural modification (rather than simple peripheral derivatization) of existing natural products. ${ }^{[6]}$ Based on our long-standing interest in epothilones as lead structures for anticancer drug discovery (Fig.), this research has also involved the synthesis and biological investigation of different types of aza-epothilones ('azathilones'), which are characterized by the replacement of a backbone carbon atom by nitrogen in the epothilone macrocycle. ${ }^{[6 c, d, 7]} \mathrm{We}$ have referred to the resulting analogs as 'non-natural' natural products, ${ }^{[8,9]}$ as they still retain most of the (two-dimensional) structural features of the natural product lead; at the same time they are structurally unique, as the incorporation of a backbone nitrogen atom places them outside of the general scope of the natural biosynthetic machinery for polyketide synthesis. ${ }^{[10]}$ As a result of these studies we discovered that 12-aza-epothilone (1) (Fig.) exhibits significant antiproliferative activity, which is still in the $100 \mathrm{nM}$ range (i.e. only $15-50$-fold lower than for Epo A). ${ }^{[6 \mathrm{~d}]}$
${ }^{\star}$ Correspondence: Prof. Dr. K.-H. Altmann ${ }^{a}$

Tel.: +41446337390

Fax: +41446331360

E-Mail: karl-heinz.altmann@pharma.ethz.ch

aswiss Federal Institute of Technology (ETH) Zürich

Institute of Pharmaceutical Sciences

ETH Hönggerberg, $\mathrm{HCl} \mathrm{H} 405$

$\mathrm{CH}-8093$ Zürich

bCurrent Address: Carbogen-Amcis AG,

Neulandweg 5, Hunzenschwil

'Novartis Institute for Biomedical Research, Basel

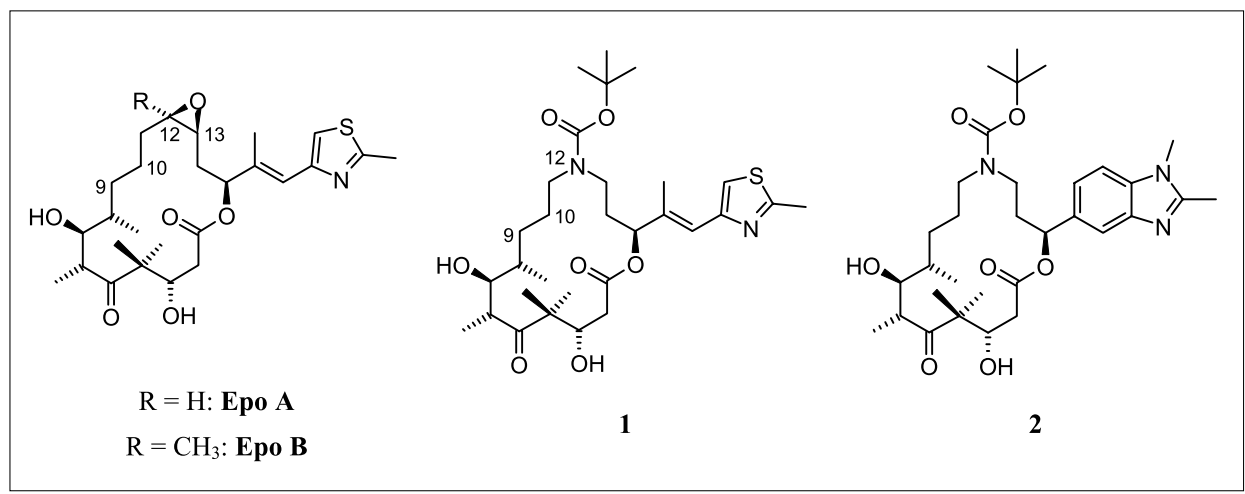

Fig. 
Unfortunately, our first generation synthesis of $\mathbf{1}$ and related analogs was relatively inefficient and tedious, ${ }^{[6 \mathrm{~d}]}$ which led us to investigate alternative synthetic routes to this class of compounds. At the same time, we have also investigated the effects of the replacement of the natural epothilone side chain in $\mathbf{1}$ with a dimethylbenzimidazole moiety, leading to analog $\mathbf{2}$ as an additional target structure for synthesis (Fig.). For the latter modification we have previously shown that it produces a significant enhancement in antiproliferative activity in combination with the natural epothilone macrocycle. ${ }^{[6 a, b, 11]}$

\section{Results and Discussion}

Macrocycle formation through ringclosing olefin metathesis (RCM) featured as a particularly attractive approach to the target azathilones $\mathbf{1}$ and $\mathbf{2}$, as it would also provide specific unsaturated analogs (as the immediate cyclization products), which could be interesting new antiproliferative agents in their own right. ${ }^{[12]}$ As shown in Schemes 1 and 2, our RCM-based synthesis of target structure 1 and its 9,10-didehydro derivative 10 involved three key strategic steps, namely

i) the stereoselective aldol reaction between aldehyde $3^{[13]}$ and ketone $4^{[14]}(d r$ $=8: 1)$ (Scheme 1),

ii) esterification of carboxylic acid 7 with the unsaturated alcohol 8, ${ }^{[15]}$ (Scheme 2) and

iii) RCM with diene 9.

Initial attempts to cyclize 9 employing the first-generation Grubbs catalyst ${ }^{[16]}$ met with complete failure and no conversion was observed. In contrast, the use of the dihydroimidazol-2-ylidene-based secondgeneration catalyst ${ }^{[16]}$ produced the cyclic olefin in good yield $(68 \%)$ and with high $E$ selectivity (>20:1). Similar observations were made in the cyclization of diene 12, which gave macrolactone $\mathbf{1 3}$ in excellent yield and with exclusive $E$ selectivity (Scheme 3). No trace of the corresponding $Z$ product could be isolated. Unfortunately, the efficiency of the cyclization reaction in both cases was thwarted by serious difficulties with the subsequent reduction of the 9,10-double bond, which proved to be extremely sluggish under all experimental conditions investigated (thus leading to low yields and also side reactions such as reductive ester cleavage with $\mathrm{H}_{2} / \mathrm{Pd}-\mathrm{C}$ without reduction of the double bond in the case of 13). The most effective method for transforming $\mathbf{1 0}$ and $\mathbf{1 3}$ into $\mathbf{1}$ and 2, respectively, involved the use of in situ generated diimide $^{[17]}$ (Schemes 2 and 3). However, even under these conditions 1 was obtained in only $15 \%$ isolated yield $(30 \%$ based on recovered starting material) at $40 \%$ conver-

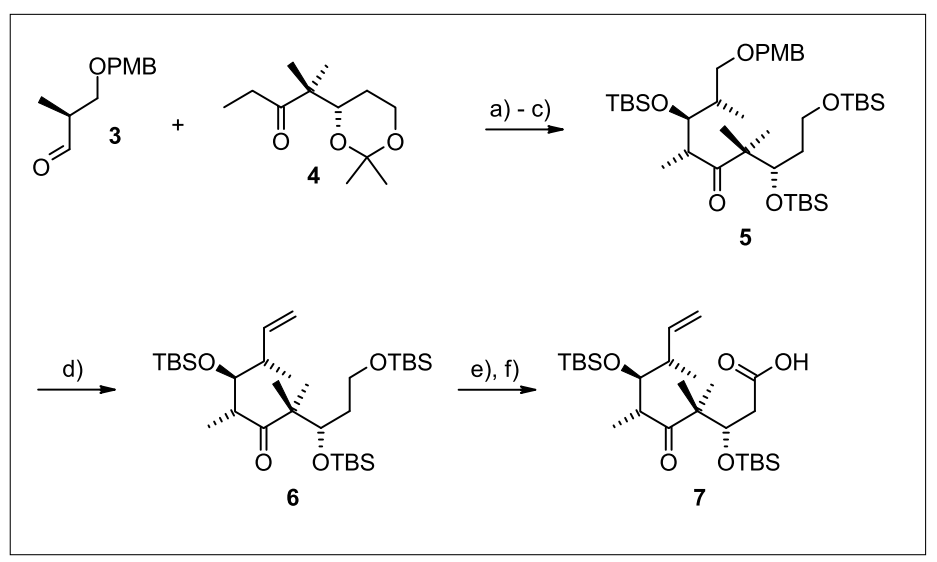

Scheme 1. a) 4, LDA, $-78{ }^{\circ} \mathrm{C}, 5 \mathrm{~h}$, then addition of $3,-90{ }^{\circ} \mathrm{C}, 75 \mathrm{~min}, 76 \%$, $d r=8: 1$; b) PPTS, MeOH, RT, 20 h, 86\%; c) (i) TBSOTf, 2,6-lutidine, $-78^{\circ} \mathrm{C}$ $\rightarrow$ RT, 1.5 h; (ii) flash chromatography, 76\%; d) (i) $\mathrm{H}_{2} / \mathrm{Pd}-\mathrm{C}, \mathrm{MeOH}, \mathrm{RT}, 20$ h; (ii) TPAP, NMO, 4-Å MS, $\mathrm{CH}_{2} \mathrm{Cl}_{2}, \mathrm{RT}, 1 \mathrm{~h}$; (iii) $\mathrm{MePPh}_{3} \mathrm{Br}$, LiHMDS, THF, $0{ }^{\circ} \mathrm{C}, 1.5 \mathrm{~h}, 79 \%$ (three steps); e) CSA (1.0 equiv.), $\mathrm{CH}_{2} \mathrm{Cl}_{2} / \mathrm{MeOH} 1: 1,0{ }^{\circ} \mathrm{C}$, $1 \mathrm{~h}, 87 \%$; f) PDC (11 equiv.), DMF, RT, 64 h, $85 \%$.

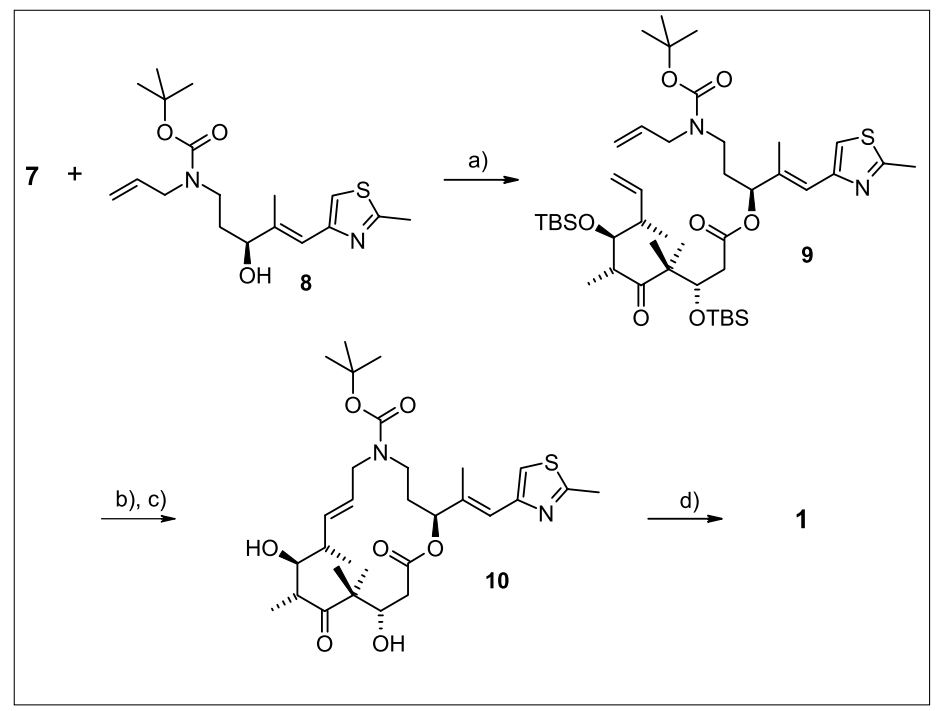

Scheme 2. a) 8 (1.2 equiv.), DCC (1.3 equiv.), DMAP (0.3 equiv.), $\mathrm{CH}_{2} \mathrm{Cl}_{2}$, $0{ }^{\circ} \mathrm{C}, 30 \mathrm{~min}, \mathrm{RT}, 6 \mathrm{~h}, 77 \%$; b) 2nd generation Grubbs catalyst $(0.09$ equiv., incremental addition), $\mathrm{CH}_{2} \mathrm{Cl}_{2}$, refl., $24 \mathrm{~h}, 68 \%$ (pure $E$ isomer); c) $\mathrm{HF} \bullet$ pyridine, pyridine, THF, RT, $4.5 \mathrm{~h}, 65 \%$; d) $\mathrm{KO}_{2} \mathrm{C}-\mathrm{N}=\mathrm{N}-\mathrm{CO}_{2} \mathrm{~K}$ (excess), $\mathrm{AcOH}, \mathrm{CH}_{2} \mathrm{Cl}_{2}$, refl., $15 \%$ (30\% based on recovered starting material); pure 1 obtained through purification by preparative HPLC.

sion and after purification by preparative HPLC. Macrocycle 2 was obtained in 31\% yield from 13 after HPLC purification.

The above RCM approach provided sufficient amounts of 2 for initial biological testing, but it was clear that more extensive profiling of this compound (including, perhaps, in vivo studies) would require the development of an alternative synthetic route, in order to facilitate the preparation of larger quantities of material. In light of highly promising early biological data (vide infra), we thus embarked on the elaboration of an alternative route to 2 that would be based on macrocyclization through ester bond formation rather than RCM. As illustrated in Scheme 4, this approach employed the reductive amination of aldehyde 16 with amine 15 (obtained in three steps from the known protected tetrol $\mathbf{1 4}^{[14 \mathrm{a}]}$ ) to assemble the hetero-aliphatic skeleton of 2. As the highly polar reductive amination product was difficult to purify, it was directly converted to the corresponding $\mathrm{N}$ tert-butoxycarbonyl derivative $(60 \%$ yield, based on amine 15). Selective cleavage of the primary TBS-ether with CSA, oxidation of the resulting free alcohol with PDC, and removal of the TBS-protecting group from $\mathrm{C}^{15}-\mathrm{O}$ with $\mathrm{TBAF}$ furnished seco 


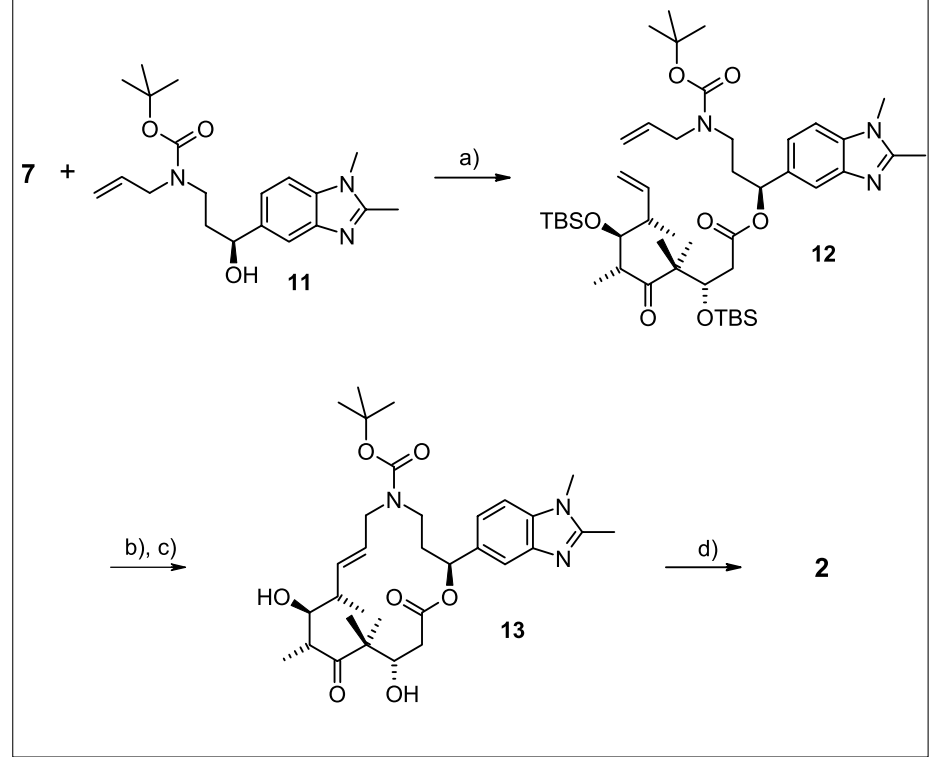

Scheme 3. a) $11 \mathrm{DCC}$ (1.2 equiv.), DMAP (0.3 equiv.), $\mathrm{CH}_{2} \mathrm{Cl}_{2}, 0{ }^{\circ} \mathrm{C}, 15 \mathrm{~min}$, RT, $15 \mathrm{~h}, 60 \%$; b) 2 nd generation Grubbs catalyst ( 0.15 equiv., incremental addition), $\mathrm{CH}_{2} \mathrm{Cl}_{2}$, refl., $8 \mathrm{~h}, 85 \%$; c) HF•pyridine, pyridine, THF, RT, $4 \mathrm{~h}$, $70 \%$; d) $\mathrm{KO}_{2} \mathrm{C}-\mathrm{N}=\mathrm{N}-\mathrm{CO}_{2} \mathrm{~K}$ (excess), $\mathrm{AcOH}, \mathrm{CH}_{2} \mathrm{Cl}_{2}$, refl., $31 \%$; pure 2 obtained through purification by preparative HPLC.

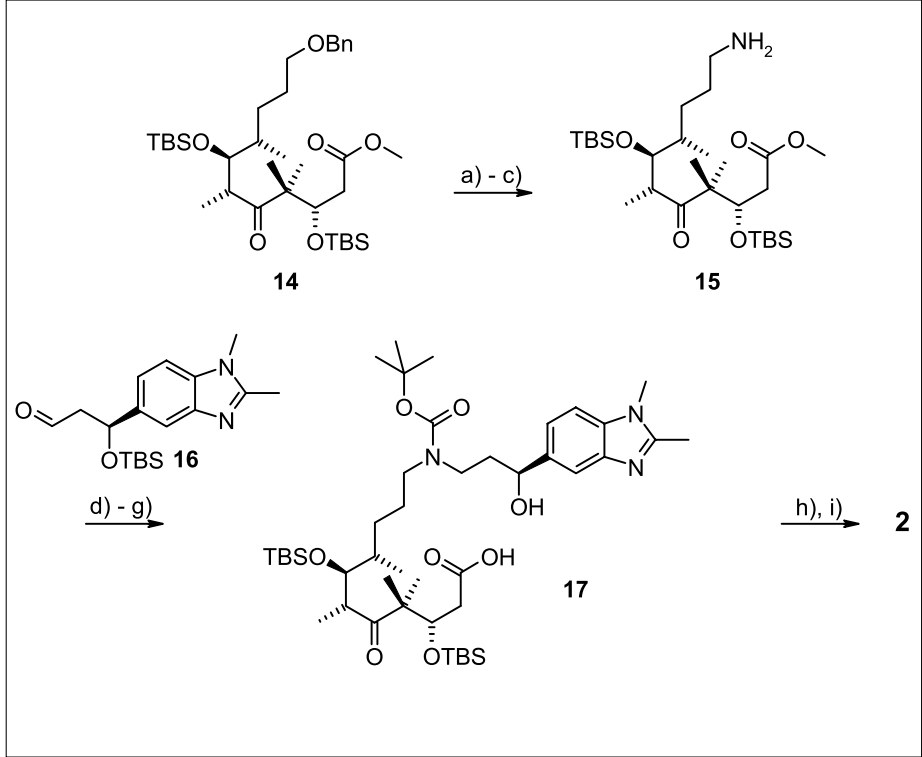

Scheme 4. a) $\mathrm{H}_{2}$ /Pd-C, EtOAc, RT, $62 \mathrm{~h}, 86 \%$; b) $\mathrm{HN}_{3}$, DEAD, $\mathrm{PPh}_{3}$, THF, $0{ }^{\circ} \mathrm{C}, 25 \mathrm{~min}, \mathrm{RT}, 30 \mathrm{~min}, 96 \%$; c) $\mathrm{H}_{2} / \mathrm{Pd}-\mathrm{C}, \mathrm{MeOH}, \mathrm{RT}, 3 \mathrm{~h}, 92 \%$; d) (i) 16 (1.1 equiv.), $\mathrm{NaBH}(\mathrm{OAc})_{3}$ (1.6 equiv.), $\mathrm{AcOH}$ (2.0 equiv.), 4- $\AA \mathrm{MS}, \mathrm{RT}, 2.5 \mathrm{~h}$; (ii) $\mathrm{BOC}_{2} \mathrm{O}, \mathrm{Et}_{3} \mathrm{~N}, \mathrm{THF}, 0{ }^{\circ} \mathrm{C}, 45 \mathrm{~min}, 60 \%$ (two steps); e) $\mathrm{CSA}$ (1.1 equiv.), $\mathrm{CH}_{2} \mathrm{Cl}_{2} / \mathrm{MeOH} 1: 1,0{ }^{\circ} \mathrm{C}, 3 \mathrm{~h}, 80 \%$; f) PDC (15 equiv.), DMF, RT, $24 \mathrm{~h}, 50 \%$; g) TBAF (6 equiv.), THF, RT, $24 \mathrm{~h}$; h) 2,4,6- $\mathrm{Cl}_{3} \mathrm{C}_{6} \mathrm{H}_{2} \mathrm{C}(\mathrm{O}) \mathrm{Cl}, \mathrm{Et}_{3} \mathrm{~N}, \mathrm{THF}, 0^{\circ} \mathrm{C}$, $20 \mathrm{~min}$, then diluted with toluene and added to a solution of DMAP in toluene, $75{ }^{\circ} \mathrm{C}, 1 \mathrm{~h}, 44 \%$ (two steps); i) HF•pyridine, pyridine, THF, RT, 2.5 h, then preparative HPLC, $40 \%$. acid 17. Cyclization of $\mathbf{1 7}$ under Yamaguchi conditions ${ }^{[18]}$ produced fully protected 2 (44\% based on $\mathrm{C}^{15}$-O-TBS-protected 17 ). Subsequent selective removal of the TBSprotecting groups with $\mathrm{HF} \bullet$ pyridine gave target structure 2 in $40 \%$ yield (after HPLC purification).

As demonstrated by the data summarized in the Table, azathilone $\mathbf{2}$ is a highly potent antiproliferative agent, which inhibits the growth of different types of drugsensitive human cancer cell lines (A549, HCT-116, PC-3M, KB-31) with low nM $\mathrm{IC}_{50}$-values. The antiproliferative activity of the compound against these cell lines is thus comparable with that of Epo A. Similarly, 2 induces tubulin polymerization in vitro with similar potency as Epo A (Table), which strongly suggests that inhibition of human cancer cell proliferation by $\mathbf{2}$, as for natural epothilones, is a consequence of interference with microtubule functionality. This view is also in line with the fact that treatment of cancer cells with azathilone 2 results in cell cycle arrest at G2/M, [8] which mirrors the effects on the cell cycle observed upon treatment with Epo A or B. ${ }^{[7]}$ Compound 2 is $>60$-fold more potent against drug-sensitive human cancer cells than the corresponding parent (natural sidechain-containing) azathilone 1 (Fig.); this potency increase dramatically exceeds the potency-enhancing effects previously observed for the dimethylbenzimidazole side chain in combination with polyketide-based macrocycles (2-15-fold). ${ }^{[6 a, b, 11]}$ Equally in- triguing is the observation that compounds 10 and 13, both of which incorporate a trans double bond between $\mathrm{C} 9$ and $\mathrm{C} 10$, are significantly less potent than the fully saturated azathilones $\mathbf{1}$ and $\mathbf{2}$, respectively (both at the level of tubulin polymerization as well as cellular activity; Table, data for $\mathbf{1 0}$ not shown). These findings are in marked contrast to the effects observed for Epo B and $\mathrm{D}$, where the introduction of a trans double bond between $\mathrm{C} 9$ and $\mathrm{C} 10$ results in enhanced (!) cellular potency, ${ }^{[17]}$ and they may be indicative of differences in the bioactive conformation between azathilone-type analogs and natural epothilones. [19]

Unfortunately, azathilone $\mathbf{2}$ is significantly less potent against the multidrug-re- sistant cervix carcinoma cell line KB-8511 than the drug-sensitive parental KB-31 line, which indicates that $\mathbf{2}$ is a substrate for the $\mathrm{P}$ gp efflux pump. However, we have recently shown that the susceptibility of polyketidebased epothilone analogs to P-gp-mediated drug efflux can be modulated through adjustments in compound lipophilicity ${ }^{[20]}$ and this strategy will also be explored for lead structure 2 .

\section{Conclusions}

In summary, we have achieved the total synthesis of two representative examples of a new class of highly potent microtubule-

Table. Tubulin-polymerizing and antiproliferative activity of azathilones $\mathbf{1}, \mathbf{2}$, and $\mathbf{1 3}$

$\begin{array}{ccccccc}\text { Compound } & \begin{array}{c}\mathrm{EC}_{50} \text { Tubulin } \\ \text { polymerization } \\ {[\mu \mathrm{M}]^{\mathrm{a}}}\end{array} & \mathrm{A} 549 & \mathrm{HCT}-116 & \mathrm{PC}-3 \mathrm{M} & \mathrm{KB}-31 & \mathrm{~KB}-8511 \\ \mathbf{1} & 5.6 \pm 0.4 & 130 \pm 24 & 110 \pm 19 & 126 \pm 22 & 31 & 105 \\ \mathbf{2} & 3.9 \pm 0.6 & 1.9 \pm 0.4 & 1.6 \pm 0.5 & 2.3 \pm 0.6 & 0.34 \pm 0.15 & 222 \pm 48 \\ \mathbf{1 3} & 9.1 \pm 0.7 & 920 \pm 85 & 1009 \pm 71 & 973 \pm 64 & \mathrm{ND}^{\mathrm{a}} & \mathrm{ND}^{\mathrm{c}} \\ \text { Epo A } & 4.6 \pm 0.5 & 3.2 \pm 0.5 & 2.2 \pm 0.3 & 3.4 \pm 0.4 & 2.15 & 1.91\end{array}$

${ }^{a}$ Concentration required to induce $50 \%$ of the maximum tubulin polymerization achievable with the respective compound ( $10 \mu \mathrm{M}$ of porcine brain tubulin). ${ }^{\mathrm{b}} \mathrm{C}_{50}$-values for human cancer cell growth inhibition. KB-31, KB-8511: cervix; A549: lung; HCT-116: colon; PC-3M: prostate. KB-8511 is a P-glycoprotein 170 (P-gp170)-overexpressing multidrug-resistant subline of the KB-31 parental line. ${ }^{\mathrm{C}}$ Not determined. Data are from ref. 8. 
stabilizing agents, which are based on an aza-macrolide backbone and which we have termed azathilones. While the conception of these compounds is closely connected to the structure of natural epothilones (hence the name 'azathilones'), given the degree of structural divergence from the natural epothilone template, in particular in the case of $\mathbf{2}$, they may be considered as members of a distinct group of 'non-natural' natural products with unique structural features and, as indicated by some preliminary SAR data, a unique SAR profile.

Received: February 2, 2007

[1] G. M. Cragg, D. J. Newman, Pure Appl. Chem. 2005, 77, 7-24.

[2] S.L. Schreiber, Science 2000, 287, 19641969.

[3] M. D. Burke, S. L. Schreiber, Angew. Chem., Int. Ed. 2004, 43, 46-58.

[4] R. Breinbauer, I. R. Vetter, H. Waldmann, Angew. Chem., Int. Ed. 2002, 41, 28782890.

[5] a) M. A. Koch, H. Waldmann, Drug Discovery Today 2005, 10, 471-483; b) M. A. Koch, A. Schuffenhauer, M. Scheck, S. Wetzel, M. Casaulta, A. Odermatt, P. Ertl, H. Waldmann, Proc. Natl. Acad. Sci. USA 2005, 102, 17272-7277; c) M. A. Koch, L.-O. Wittenberg, S. Basu, D. A. Jeyaraj, E. Gourzoulidou, K. Reinecke, A. Odermatt, H. Waldmann, Proc. Natl. Acad. Sci. USA 2004, 101, 16721-16726.

[6] a) F. Cachoux, T. Isarno, M. Wartmann, K.-H. Altmann, ChemBioChem 2006, 7 , 54-57; b) F. Cachoux, T. Isarno, M. Wartmann, K.-H. Altmann, Angew. Chem., Int. Ed. 2005, 44, 7469-7473; c) F. Cachoux, F. Schaal, A. Teichert, T. Wagner, K.-H. Altmann, Synlett 2004, 2709-2712; d) K.H. Altmann, A. Flörsheimer, G. Bold, G. Caravatti, M. Wartmann, Chimia 2004, 58, 686-690.

[7] For reviews on epothilones see e.g.: a) G. Höfle, H. Reichenbach, in 'Anticancer Agents from Natural Products', Eds. G. M. Cragg, D. G. I. Kingston, D. J. Newman, CRC Press LLC, Boca Raton, Fla, 2005, pp. 413-450; b) K.-H. Altmann, Curr. Pharm. Des. 2005, 11, 1595-1613; c) K.-H. Altmann, Org. Biomol. Chem. 2004, 2137-2152; d) C. R. Harris, S. J. Danishefsky, J. Org. Chem. 1999, 64, 84348456; e) K. C. Nicolaou, F. Roschangar, D. Vourloumis, Angew. Chem., Int. Ed. Engl. 1998, 37, 2014-2045.

[8] F. Feyen, J. Gertsch, M. Wartmann, K.-H. Altmann, Angew. Chem., Int. Ed. 2006, 45, 5880-5885.

[9] For a previous use of the term "non-natural' natural product' see: L. F. Tietze, H. P.
Bell, S. Chandrasekar, Angew. Chem., Int. Ed. 2003, 42, 3996-4028.

[10] For a review, see e.g.: C. A. Walsh, Curr. Opin. Chem. Biol. 1999, 3, 598-606.

[11] K.-H. Altmann, G. Bold, G. Caravatti, A. Flörsheimer, V. Guagnano, M. Wartmann, Bioorg. Med. Chem. Lett. 2000, 10, 2765 2768.

[12] a) A. Rivkin, T.-C. Chou, S. J. Danishefsky, Angew. Chem., Int. Ed. 2005, 44, 2838-2850; b) A. Rivkin, F. Yoshimura, G. Fumihiko, A. E. Gabarda, Y. S. Cho, T.-C. Chou, H. Dong, S. J. Danishefsky, J. Am. Chem. Soc. 2004, 126, 10913-10922; c) R. L. Arslanian, L. Tang, S. Blough, W. Ma, R.-G. Qiu, L. Katz, J. R. Carney, J. Nat. Prod. 2002, 65, 1061-1064; d) I. H. Hardt, H. Steinmetz, K. Gerth, F. Sasse, H. Reichenbach, G. Höfle, J. Nat. Prod. 2001, 64, 847-856.

[13] J. D. White, R. G. Carter, K. F. Sundermann, M. Wartmann, J. Am. Chem. Soc. 2001, 123, 5407-5413. Aldehyde 3 was obtained through Swern oxidation of the corresponding primary alcohol and directly used in step a) of Scheme 1 without purification. The yield reported for this step assumes the oxidation to have been quantitative.

[14] a) K.-H. Altmann, G. Bold, G. Caravatti, D. Denni, A. Flörsheimer, A. Schmidt, G. Rihs, M. Wartmann, Helv. Chim. Acta 2002, 85, 4086-4110; b) D. Schinzer, A. Bauer, O. M. Böhm, A. Limberg, M. Cordes, Chem. Eur. J. 1999, 5, 24832491.

[15] The synthesis of olefins $\mathbf{8}$ and $\mathbf{1 1}$ will be described elsewhere.

[16] For recent reviews on olefin metathesis see e.g.: a) R. H. Grubbs, Tetrahedron 2004, 60, 7117-7140; b) T. M. Trnka, R. H. Grubbs, Acc. Chem. Res. 2001, 34, 18-29.

[17] a) F. Yoshimura, A. Rivkin, A. E. Gabarda, T.-C. Chou, H. Dong, G. Sukenick, F. F. Morel, R. E. Taylor, S. J. Danishefsky, $A n$ gew. Chem., Int. Ed. 2003, 42, 2518-2521; b) K. Biswas, H. Lin, J. T. Njardson, M. D. Chappell, T.-C. Chou, Y. Guan, W. P. Tong, L. He, S. B. Horwitz, S. J. Danishefsky, J. Am. Chem. Soc. 2002, 124, 9825-9832.

[18] J. Inanaga, K. Hirata, H. Saeki, T. Katsuki, M. Yamaguchi, Bull. Chem. Soc. Jpn. 1979, 52, 1989-1993.

[19] SAR studies on azathilones $\mathbf{1}$ had also included the $\mathrm{N}$-unsubstituted version of these compounds, which proved to be completely inactive. For this reason the free amine corresponding to 2 (N12 unsubstituted) was not investigated in the current study.

[20] F. Cachoux, T. Isarno, M. Wartmann, K.H. Altmann, Synlett 2006, 1384-1388. 